\title{
Effect of Stimulating Drinks on the Mechanical Properties of Composite Resin Provisional Restorative Materials
}

\author{
Abdulelah M BinMahfooz ${ }^{1}$, Osama A Qutub², Ghadeer I Basunbul ${ }^{3}$
}

\begin{abstract}
Aim: The objective of the study is to examine the effects of the consumption of caffeinated drinks common to the Saudi population regarding the mechanical properties of composite resin restorative provisional materials.

Materials and methods: An in vitro approach has been utilized to analyze the flexural strength and microhardness of three different composite provisional restorative materials: Temphas $\mathrm{e}^{\mathrm{TM}}$, Protemp ${ }^{\mathrm{T} M}$, and CAD Temp ${ }^{\oplus}$ monoColor, when immersed in three different caffeinated drinks: Arabic coffee, American black coffee, and cappuccino, distilled water was used as the control group for a duration of seven days ( $n=10$ for each test). Results were analyzed using two-way ANOVA and Tukey HSD tests.

Results: All beverages significantly reduced the flexural strength of different composite provisional restorative materials investigated in the study. All beverages significantly reduced the microhardness of the Temphase ${ }^{T M}$ material. Arabic coffee did not significantly affect the microhardness values of the Protemp ${ }^{\mathrm{TM}}$ material and did not have an impact on the microhardness of the CAD Temp ${ }^{\circledR}$ material.

Conclusion: The surface microhardness and flexural strength of different composite resin materials were altered after emersion in different caffeinated drinks.

Clinical significance: As excessive consumption of caffeinated beverages have a negative effect on the durability and longevity of the different composite resin provisional restorative materials, dentists should counsel patients with provisional restorations to reduce the detrimental effect associated with excessive consumption of these beverages.
\end{abstract}

Keywords: Arabic coffee, Caffeinated beverages, Provisional composite restorative materials, Stimulating drinks.

World Journal of Dentistry (2019): 10.5005/jp-journals-10015-1628

\section{INTRODUCTION}

While introducing a variety of widescale advertising, stimulating caffeinated drinks becomes increasingly popular across the globe. A common belief is that the consumption of these drinks can enhance peoples' focus, attention, performance, and energy. ${ }^{1}$ Although most of those common beliefs are not scientifically proven, the consumption of these drinks has shown a consistent and persistent rise by amateur and professional athletes, adolescents, as well as adults. ${ }^{2,3}$

Stronger variety of caffeinated drinks like cappuccino has excessive caffeine, low alkaline, and higher acidic content. Excessive consumption of acidic beverages and food increases the acidic challenge to teeth that results in the negative consequences to the oral environment. ${ }^{4}$ Moreover, all dental restorative materials have exhibited degradation over time, following experimentation under acidic conditions. It is almost impossible to isolate and segregate restorative materials that have successfully overcome the acidic challenges and subsequently retained their physical, chemical, and mechanical properties. ${ }^{5,6}$ The excessive consumption of caffeinated drinks and other beverages with high acidic content have significant negative effects on the quality, durability, and the longevity of the different restorative materials used in dentistry. ${ }^{7,8}$ Xavier et al. reported esthetic restorative material's microhardness loss associated with repeated exposure to acidic beverages. ${ }^{9}$ Badra et al. reported the significant deterioration of composite restoration surface roughness and microhardness when exposed to acidic beverages for prolonged period of time. ${ }^{10}$

The consumption of caffeinated drinks has come to be an existential part of food and drink consumption regimen all over the world. Each $100 \mathrm{~mL}$ (3-ounce) of cappuccino contains about $20 \mathrm{mg}$ of

\footnotetext{
${ }^{1-3}$ Department of Oral and Maxillofacial Prosthodontics, Faculty of Dentistry, King Abdulaziz University, Jeddah, Saudi Arabia

Corresponding Author: Ghadeer I Basunbul, Department of Oral and Maxillofacial Prosthodontics, Faculty of Dentistry, King Abdulaziz University, Jeddah, Saudi Arabia, Phone: +966 555595707, e-mail: gbasunbal@kau.edu.sa

How to cite this article: BinMahfooz AM, Qutub OA, et al. Effect of Stimulating Drinks on the Mechanical Properties of Composite Resin Provisional Restorative Materials. World J Dent 2019;10(3):192-196.

Source of support: Nil

Conflict of interest: None
}

caffeine. Therefore, an 8-ounce cup of cappuccino has about $50 \mathrm{mg}$ of caffeine. According to Nescafe, each 6-ounce cup of their coffee contains about $65 \mathrm{mg}$ of caffeine. However, Arabic coffee mainly contains cardamom that is mixed with lesser amounts of minimally roasted coffee. Other spices such as cloves, ginger, and saffron may be added..$^{11}$ The amount of caffeine in these stimulating drinks could have an impact on the physical-mechanical properties of the dental restorative materials. The microhardness and roughness of composite resin material may be altered with the consumption of strongly caffeinated drinks. All these factors may affect the durability and the longevity of the resin restorative materials.

Up to our knowledge, there are limited researches conducted to analyze the effects of consuming stimulating drinks like Cappuccino, Nescafe, Latte, Nespresso, Expresso, Arabic or Turkish coffee on the mechanical properties of dental restorative materials. Awliya et al. reported the insignificant effect of different types of

(O) The Author(s). 2019Open Access This article is distributed under the terms of the Creative Commons Attribution 4.0 International License (https://creativecommons. org/licenses/by-nc/4.0/), which permits unrestricted use, distribution, and non-commercial reproduction in any medium, provided you give appropriate credit to the original author(s) and the source, provide a link to the Creative Commons license, and indicate if changes were made. The Creative Commons Public Domain Dedication waiver (http://creativecommons.org/publicdomain/zero/1.0/) applies to the data made available in this article, unless otherwise stated. 
caffeinated drinks on composite resin fillings. However, according to Awliya et al. and AISamadani et al., all composite restorative materials exhibited significant changes in color only with aging. ${ }^{12,13}$

The objective of this in vitro study is to shed light on the effects of the consumption of common caffeinated drinks in Saudi Arabia regarding the flexural strength and microhardness of composite resin restorative provisional materials.

\section{Materials and Methods}

An in vitro approach has been utilized to analyze the effect of three variants of caffeinated drinks: Arabic coffee, American black coffee, and cappuccino on three provisional composite restorative materials: Temphase ${ }^{\mathrm{TM}}{ }^{\text {, Protemp }}{ }^{\mathrm{TM}}$, and CAD Temp ${ }^{\circledast}$ monoColor. Table 1 lists the materials, their chemical composition, and manufacturers evaluated in the study. Table 2 lists the different caffeinated beverages, $\mathrm{pH}$ values, and their manufacturers used in the study. The $\mathrm{pH}$ of each beverage was measured using a portable $\mathrm{pH}$ meter $(\mathrm{PH} 500 \mathrm{pH} / \mathrm{mV} /$ TEMP Meter, Orion Research, Boston, MA, USA). Three readings were obtained for each beverage and the mean was recorded. The study was conducted at the Advanced Dental Research Laboratory Center of King Abdulaziz University, Jeddah, Saudi Arabia.

\section{Specimens Preparations}

A polytetrafluoroethylene mold (Fig. 1) was fabricated to provide $25 \times 2 \times 2 \mathrm{~mm}$ standardized bars from the provisional restorative

Table 1: Materials used in the study

\begin{tabular}{lll}
\hline Product & Material type & Manufacturer \\
\hline Temphase $^{\mathrm{TM}}$ & $\begin{array}{l}\text { Self-cure bis-methacryl } \\
\text { resin composite }\end{array}$ & $\begin{array}{l}\text { Kerr Corp., Orange } \\
\text { California }\end{array}$ \\
Protemp $^{\text {TM }}$ & Self-cure bis-acryl & 3M-ESPE. Seefeld \\
& composite & Germany \\
CAD Temp $^{\circledast}$ & Micro filled, poly methyl & Vita Zahnfabrik, Bad \\
monoColor & methacrylate & Sackingen, Germany \\
\hline
\end{tabular}

Table 2: Beverages used in the study

\begin{tabular}{lll}
\hline Product & $p H$ value & Manufacturer \\
\hline Distilled water & 7 & Control \\
Arabic coffee & 6.8 & AL Rifai, Saudi Arabia \\
American black coffee & 4.8 & Nescafe, Saudi Arabia \\
Cappuccino & 6 & Nescafe, Saudi Arabia \\
\hline
\end{tabular}

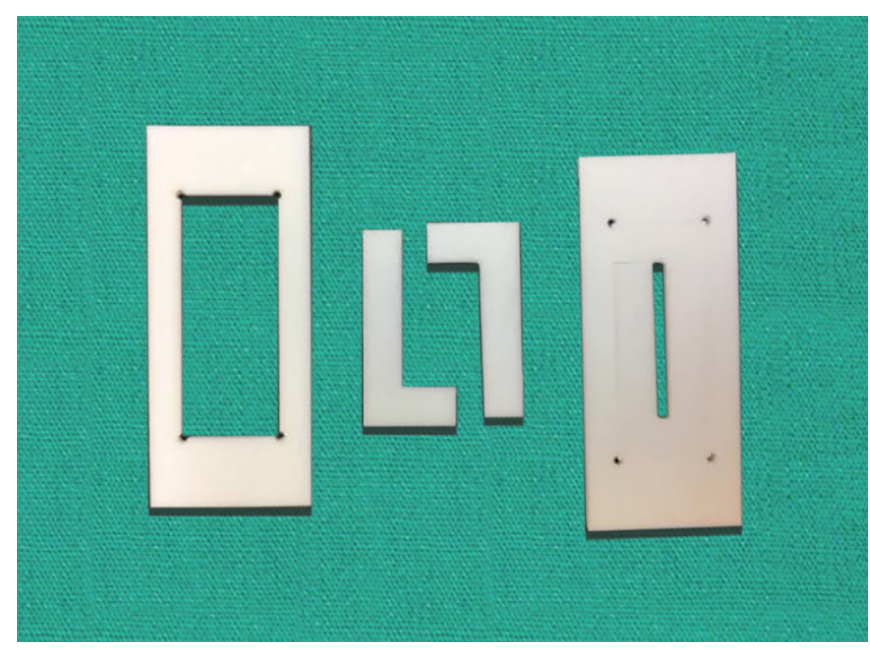

Fig. 1: Polytetrafluoroethylene mold provide $25 \times 2 \times 2 \mathrm{~mm}$ bars materials used in the study, according to American Dental Association Specification no. 27. A total of 240 samples was provided, 80 samples from each provisional restorative material under investigation. TemPhase ${ }^{\mathrm{TM}}$ and Protemp ${ }^{\mathrm{TM}}$ specimens were prepared by mixing the material according to their manufacturer instructions', then injected into a slot created by the mold and held under compression with a glass slab for complete polymerization. CAD Temp ${ }^{\oplus}$ monoColor were milled into the standardized bars using the KaVo Everest ${ }^{\oplus}$ CAD/CAM System (Everes ${ }^{\oplus} \mathrm{t}$, KaVo Dental $\mathrm{GmbH}$, Germany). Before testing, the specimens were reserved for one day in deionized water. After the completion of specimens' preparation, all specimens were carefully inspected, measured, and excluded for the presence of any defects. A flat surface was obtained by polishing the specimen with fine and ultra-fine aluminum oxide abrasive disks. A total of 240 samples, 80 samples from each material under investigation were retrieved. A set of 20 samples from each provisional material was stored in a container filled with $20 \mathrm{~mL}$ of each of the three drinks used in the study and the control group in distilled water for 7 days at $37^{\circ}$ in a Memmert oven (Cooled vacuum oven V0200Cool, Memmert GmbH + Co. KG, Schwabach) before being tested. All the solutions were refilled, and the $\mathrm{pH}$ of those solutions was recorded on daily basis. All the samples were cleaned with water and dried using air stream after the immersion period before testing.

\section{Flexural Strength Testing}

To evaluate the flexural strength, a three-point test was performed for all the specimens using an Instron Universal Testing Machine (AGS-500; Shimadzu, Kyoto, Japan). The bars were placed on a three-point fixture that has a $15 \mathrm{~mm}$ span where $10 \mathrm{kN}$ load was applied at a crosshead speed of $0.5 \mathrm{~mm} /$ minute. Flexural strength was directly computed via a computer connected to the Instron Machine. The flexural strength values of 10 samples from each provisional material under investigation were recorded per specimen in MPa unit.

\section{Microhardness Testing}

A Micromet Buehler Microhardness tester (Buehler, Lack Bluff Illinois, USA) was used to measure Vickers microhardness. Each individual specimen was fixed in the apparatus in a 90-degree relation to the indenter. The load applied was $300 \mathrm{~g}$ in a duration of 30 seconds per indentation. Each specimen was tested in three different locations at the center of each specimen and there were $1 \mathrm{~mm}$ apart. The mean of the three readings was considered as the microhardness value of the specimen. The microhardness value of each specimen was calculated by taking the average of the three readings and then recorded. Vickers microhardness value was recorded for 10 specimens from each provisional material under investigation in the HV unit.

\section{Statistical Analysis}

Statistical Package for Social Sciences SPSS (IBM Corp. Released 2012. IBM SPSS Statistics for Windows, Version 21.0. Armonk, NY: IBM Corp) was used as analysis software. Descriptive statistics were presented as means and standard deviations. To assess significant changes within each group, two-way ANOVA and Tukey HSD tests were used at a significance level equal to or less than 0.05 .

\section{Results}

The results of two-way ANOVA test evaluating the flexural strength values of the different tested provisional materials in the different 
Table 3: Two-way ANOVA of the effect of different beverages on the flexural strength of the provisional restorative materials

\begin{tabular}{llrllll}
\hline ANOVA & \multicolumn{7}{l}{} & & & \\
\hline Source of variation & SS & df & MS & F & F crit \\
\hline Materials & 2085.713782 & 2 & 1042.856891 & 50.61311697 & 0.000 & 3.080387 \\
Beverages & 9045.014847 & 3 & 3015.004949 & 146.32765 & 0.000 & 2.688691 \\
Interaction & 410.7890583 & 6 & 68.46484306 & 3.322813648 & 0.005 & 2.183657 \\
Within & 2225.2837 & 108 & 20.6044787 & & & \\
Total & 13766.80139 & 119 & & & & \\
\hline
\end{tabular}

Table 4: Effect of different beverages on the flexural strength of Temphase $^{\text {TM }}$

\begin{tabular}{lllll}
\hline & $n$ & Mean $(\mathrm{MPa})$ & $\mathrm{SD}$ & p value \\
\hline Control & 10 & 90.088 & 5.267 & \\
Arabic coffee & 10 & 75.732 & 2.923 & $0.000^{*}$ \\
American black coffee & 10 & 64.925 & 3.084 & $0.000^{*}$ \\
Cappuccino & 10 & 71.694 & 0.904 & $0.000^{*}$ \\
\hline
\end{tabular}

*indicates statistically significant difference $(p<0.05)$

Table 5: Effect of different beverages on the flexural strength of Protemp ${ }^{\mathrm{TM}}$

\begin{tabular}{lllrl}
\hline & $n$ & Mean $(\mathrm{MPa})$ & \multicolumn{1}{c}{ SD } & pvalue \\
\hline Control & 10 & 89.071 & 3.229 & \\
Arabic coffee & 10 & 74.53 & 4.310 & $0.000^{*}$ \\
American black coffee & 10 & 60.597 & 11.175 & $0.000^{*}$ \\
Cappuccino & 10 & 67.493 & 1.592 & $0.000^{*}$ \\
\hline
\end{tabular}

${ }^{*}$ indicates statistically significant difference $(p<0.05)$

Table 6: Effect of different beverages on the flexural strength of $C A D$ Temp ${ }^{\circledast}$

\begin{tabular}{lllll}
\hline & $n$ & Mean $(\mathrm{MPa})$ & SD & pvalue \\
\hline Control & 10 & 92.178 & 3.194 & \\
Arabic coffee & 10 & 84.753 & 2.333 & $0.000^{*}$ \\
American black coffee & 10 & 75.448 & 2.571 & $0.000^{*}$ \\
Cappuccino & 10 & 78.815 & 4.686 & $0.000^{*}$ \\
\hline
\end{tabular}

*indicates statistically significant difference $(p<0.05)$

beverages are displayed in Table 3. Tables 4 to 6 show the mean flexural strength values in MPa, standard deviations, and significance difference of each provisional material after 7 days of immersion in the three tested beverages. Post hoc Tukey tests illustrated that all the used beverages in the study significantly reduced the flexural strength of Temphase ${ }^{\mathrm{TM}}$ (Table 4), Protemp ${ }^{\mathrm{TM}}$ (Table 5), and CAD Temp ${ }^{\circledast}$ (Table 6) when compared to the control. $p<0.05$.

The results of the two-way ANOVA test evaluating the Vickers microhardness values of the different tested provisional materials in the different beverages are displayed in Table 7. Tables 8 to 10 show the mean Vickers microhardness values in HV, standard deviations, and significance difference of each provisional material investigated in the study after 7 days of immersion period in the three tested beverages. Post hoc Tukey tests illustrated that all the used beverages significantly reduced the microhardness of the Temphase ${ }^{\mathrm{TM}}$ material (Table 8). Arabic coffee did not significantly alter the microhardness value of the Protemp ${ }^{\mathrm{TM}}$ material (Table $9, p=0.55>0.05$ ) and did not have an impact on the microhardness of the CAD Temp ${ }^{\oplus}$ material (Table 10, $p=1>0.05$ ).

\section{Discussion}

As there is an increasing demand for esthetic restorative materials, resin-based composites are being used in dentistry as reliable restorative materials due to their esthetic value, mechanical strength, and their adhesive potential to the tooth structure. ${ }^{14}$ The physical and mechanical properties of the composite resin provisional restorative materials are substantively affected with the consumption of beverages like tea, coffee, aerated, and alcoholic drinks. ${ }^{15}$ Beverages with high acidic content not only affect the structure of the composite resin, but also the characteristic of its particles, leading to undermining the longevity and the quality of restorative materials used in dental procedures. ${ }^{16,17}$ Studies claim that the degradation of resin composites in acidic environment usually happens due to bond failure between the filler particles and matrix or due to the softening effect of the acidic solution. ${ }^{18}$

The acidity of coffee, which is considered a desirable flavor, is influenced by the growing region as well as the degree of beans roasting and processing. ${ }^{19}$ Arabic coffee has a bitter flavor but almost neutral $\mathrm{pH}$ value $(\mathrm{pH}=6.8)$ as it uses the minimal quantity of lightly roasted beans cultured in Brazil, Ethiopia, Kenya, and Sudan. ${ }^{20}$ Although the American black coffee $\mathrm{pH}$ is rated as low acidic ( $\mathrm{pH}$ range from 4.5 to 6 ) when compared to citrus fruit juices ( $\mathrm{pH}$ ranges from 2 to 3 ), less is known about how different components of coffee react together. ${ }^{21}$ Addition of cream or milk usually increases the $\mathrm{pH}$ value of cappuccino to a reasonably higher $\mathrm{pH}$ value $(\mathrm{pH}=6)$. As American black coffee, cappuccino, and Arabic coffee are beverages with a low $\mathrm{pH}$ factor when compared to saliva $(\mathrm{pH}=7.4)$, they are expected not only to have a debilitating effect of the surface microhardness, but also are detrimental to the flexural

Table 7: Two-way ANOVA of the effect of different beverages on the Vickers microhardness of the provisional restorative materials

\begin{tabular}{llrllll}
\hline ANOVA & \multicolumn{1}{l}{} & & & \\
\hline Source of variation & SS & $d f$ & MS & $F$ & F lue & F crit \\
\hline Materials & 1493.216667 & 2 & 746.6083333 & 842.5673981 & 0.000 & 3.080386863 \\
Beverages & 69.625 & 3 & 23.20833333 & 26.19122257 & 0.000 & 2.688691468 \\
Interaction & 36.45 & 6 & 6.075 & 6.855799373 & 0.000 & 2.183656883 \\
Within & 95.7 & 108 & 0.886111111 & & & \\
Total & 1694.991667 & 119 & & & & \\
\hline
\end{tabular}


Table 8: Effect of different beverages on the microhardness of Temphase $^{\mathrm{TM}}$

\begin{tabular}{lllll}
\hline & $n$ & Mean $(H V)$ & $S D$ & $p$ value \\
\hline Control & 10 & 18.5 & 1.080 & \\
Arabic coffee & 10 & 17.4 & 0.516 & $0.009^{*}$ \\
American black coffee & 10 & 17.6 & 0.516 & $0.03^{*}$ \\
Cappuccino & 10 & 15.2 & 1.229 & $0.000^{*}$ \\
\hline
\end{tabular}

*indicates statistically significant difference $(p<0.05)$

Table 9: Effect of different beverages on the microhardness of Protemp ${ }^{\mathrm{TM}}$

\begin{tabular}{lllll}
\hline & $n$ & Mean $(H V)$ & SD & p value \\
\hline Control & 10 & 14 & 0.667 & \\
Arabic coffee & 10 & 13.6 & 0.516 & 0.55 \\
American black coffee & 10 & 12.8 & 0.789 & $0.025^{*}$ \\
Cappuccino & 10 & 13.2 & 0.789 & $0.037^{*}$ \\
\hline
\end{tabular}

*indicates statistically significant difference $(p<0.05)$

Table 10: Effect of different beverages on the microhardness of CAD Temp ${ }^{\oplus}$

\begin{tabular}{lllll}
\hline & $n$ & Mean $(H V)$ & $S D$ & p value \\
\hline Control & 10 & 23.2 & 1.619 & \\
Arabic coffee & 10 & 23.2 & 1.033 & 1 \\
American black coffee & 10 & 21.6 & 1.075 & $0.01^{*}$ \\
Cappuccino & 10 & 20.8 & 0.789 & $0.000^{*}$ \\
\hline
\end{tabular}

*indicates statistically significant difference $(p<0.05)$

strength of the composite resin provisional restorative materials. This study has set a precedent and is one kind of research on the effects of different coffee mixtures commonly used in Saudi Arabia on the mechanical properties of composite resin provisional restorative materials.

These provisional restorative materials are continuously bathed in saliva, which is simulated by distilled water in the study. ${ }^{22}$ They are either exposed to the above-mentioned beverages continuously or intermittently. Intermittent exposure occurs while drinking the beverage until the teeth are cleaned, ordinally by the washing effect of the saliva. However, continuous exposure that resembles the current study design may occur with the existence of defective restorations that facilitate plaque or calculus retention. Those adherent matter usually contain absorbed beverages remnants. ${ }^{23}$ Kao reported that changes in composite resin hardness occur within 7 days of immersion in chemical agents. ${ }^{24}$ For this reason, in the current study, the specimens were immersed in the tested beverages for 7 days.

Among the examined beverages, Arabic coffee did not affect the surface microhardness of Protemp ${ }^{\mathrm{TM}}$ and CAD Temp ${ }^{\circledR}$ materials, while American black coffee and Cappuccino had a negative effect on their surface hardness. All the beverages used in the study reduced the hardness of the Temphase ${ }^{\mathrm{TM}}$ material. Additionally, all the beverages examined in the study reduced the flexural strength of the tested provisional restorative materials. Caffeinated beverages may promote the leaching out of the filler particles because of the softening effect on the resin matrix.

The chemical composition of the composite resin material influences the material performance under oral condition. All dental composite restorative materials incorporate different types of inorganic fillers. According to Yak et al. and Soderhold et al., composites composed of glass fillers are more susceptible to deterioration by aqueous solutions than composites containing quartz fillers. ${ }^{23,25}$ Therefore, the variation in filler contents could contribute in the altered flexural strength and microhardness values of the studied composite resin provisional restorations in the beverages used.

Furthermore, the immersion elements and duration of the exposure of these restorative materials to the challenging beverages may affect the performance of these materials significantly. A study was performed to assess the effects of different beverages and thermocycling on tribological and mechanical properties of different dental restoration materials. The beverages were black tea and soft drink. It was concluded that the tribological and mechanical properties of nano-hybrid and nano composites were found to be less affected by beverage immersions and temperature change when compared to conventional dental restorative composites. ${ }^{26}$ Another study was conducted to examine the effects of foodsimulating liquids on the flexural strength and the hardness of a new silorane-based composite. This composite was compared with methacrylate-based composites. After polymerization, specimens were reserved in three different dietary simulating solutions for one week at $37^{\circ} \mathrm{C}$. The flexural strength and hardness were measured after conditioning. It was concluded that the siloranebased composite group had significantly higher flexural strength and hardness values when compared to methacrylate-based composites group. ${ }^{27}$

\section{Conclusion}

Within the limitation of the current in vitro study, the tested American black coffee, Arabic coffee, and cappuccino drinks have a significant negative effect on the durability and longevity of different composite resin provisional restorative materials over time. The surface microhardness and flexural strength of different composite resin materials were altered after emersion in the different caffeinated drinks. Furthermore, it was proven in the literature that caffeinated drinks produce discoloration of teeth as well as composite restorative materials. Future studies should be conducted to analyze the effects of variants of stimulating drinks on different restorative materials in regard to different mechanical and physical properties and the effect of thermocycling and different immersion periods.

\section{Acknowledgments}

The authors are very thankful to all the associated personnel in any reference that contributed in/for the purpose of this research.

\section{References}

1. Haskell CF, Kennedy DO, et al. Cognitive and mood improvements of caffeine in habitual consumers and habitual non-consumers of caffeine. Psychopharmacology 2005;179(4):813-825. DOI: 10.1007/ s00213-004-2104-3.

2. Soares PV, Tolentino AB, et al. Sports dentistry: a perspective for the future. Revista Brasileira de Educação Física e Esporte 2014;28(2): 351-358. DOI: 10.1590/1807-55092014000200351.

3. James JE, Rogers PJ. Effects of caffeine on performance and mood: withdrawal reversal is the most plausible explanation. Psychopharmacology 2005;182(1):1-8.DOI: 10.1007/s00213-005-0084-6.

4. May J, Waterhouse P. Dental erosion and soft drinks: a qualitative assessment of knowledge, attitude and behaviour using focus groups of schoolchildren. A preliminary study. Int J Paediatr Dent 2003;13(6):425-433. DOI: 10.1046/j.1365-263X.2003.00500.x. 
5. Wu W, McKinney J. Influence of chemicals on wear of dental composites. J Dent Res 1982;61(10):1180-1183. DOI: 10.1177/ 00220345820610101501.

6. Valinoti AC, Neves BG, et al. Surface degradation of composite resins by acidic medicines and pH-cycling. J Appl Oral Sci 2008;16(4): 257-265. DOI: 10.1590/S1678-77572008000400006.

7. Wongkhantee S, Patanapiradej V, et al. Effect of acidic food and drinks on surface hardness of enamel, dentine, and toothcoloured filling materials. J Dent 2006;34(3):214-220. DOI: 10.1016/ j.jdent.2005.06.003.

8. Hengtrakool C, Kukiattrakoon B, et al. Effect of naturally acidic agents on microhardness and surface micromorphology of restorative materials. Eur J Dent 2011;5(1):89.

9. Xavier AM, Sunny SM, et al. Repeated exposure of acidic beverages on esthetic restorative materials: an in vitro surface microhardness study. J Clin Exp Dent 2016;8(3):e312. DOI: 10.4317/jced.52906.

10. Badra V, Faraoni J, et al. Influence of different beverages on the microhardness and surface roughness of resin composites. Oper Dent 2005;30(2):213-219.

11. Borzangy S, Qutub OA, et al. Arabic Coffee as a Potential Alternative to Black Coffee in the Post-Bleaching Period: An in-vitro Study. Pesquisa Brasileira em Odontopediatria e Clinica Integrada 2018;18(1):4242. DOI: 10.4034/PBOCI.2018.181.93.

12. Awliya WY, Al-Alwani DJ, et al. The effect of commonly used types of coffee on surface microhardness and color stability of resinbased composite restorations. Saudi Dent J 2010;22(4):177-181. DOI: 10.1016/j.sdentj.2010.07.008.

13. Al-Samadani $\mathrm{KH}$. Color stability of restorative materials in response to Arabic coffee, Turkish coffee and Nescafe. J Contemp Dent Pract 2013;14(4):681. DOI: 10.5005/jp-journals-10024-1385.

14. Qualtrough A, Mannocci F. Tooth-colored post systems: a review. Oper Dent 2003;28(1):86-91.

15. Erdemir U, Yildiz E, et al. Effects of energy and sports drinks on tooth structures and restorative materials. World J Stomatol 2016;5(1):1-7. DOI: 10.5321/wjs.v5.i1.1.
16. Domingos PAdS, Garcia PPNS, et al. Composite resin color stability: influence of light sources and immersion media. J Appl Oral Sci 2011;19(3):204-211. DOI: 10.1590/S1678-77572011000300005.

17. Lu H, Roeder LB, et al. Effect of surface roughness on stain resistance of dental resin composites. J Esthet Restor Dent 2005;17(2):102-8. DOI: 10.1111/j.1708-8240.2005.tb00094.x.

18. Toledano M, Osorio R, et al. Sorption and solubility of resin-based restorative dental materials. J Dent 2003;31(1):43-50. DOI: 10.1016/ S0300-5712(02)00083-0.

19. Duarte SMdS, Abreu CMPd, et al. Effect of processing and roasting on the antioxidant activity of coffee brews. Food Sci Technol 2005;25(2):387-393. DOI: 10.1590/S0101-20612005000200035.

20. Camargo MBPd. The impact of climatic variability and climate change on Arabic coffee crop in Brazil. Bragantia 2010;69(1):239-247. DOI: 10.1590/S0006-87052010000100030.

21. Fowler M, Leheup P, et al. Cocoa, coffee and tea. In: Microbiology of fermented foods. Springer, 1998; pp. 128-147.

22. Turssi C, Hara A, et al. Effect of storage media upon the surface micromorphology of resin-based restorative materials. J Oral Rehabil 2002;29(9):864-871. DOI: 10.1046/j.1365-2842.2002.00926.x.

23. Yap A, Tan S, et al. Chemical degradation of composite restoratives. J Oral Rehabil 2001;28(11):1015-1021. DOI: 10.1046/j.1365-2842. 2001.00760.x.

24. Kao E. Influence of food-simulating solvents on resin composites and glass-ionomer restorative cement. Dent Mater 1989;5(3):201-208. DOI: 10.1016/0109-5641(89)90014-6.

25. Soderholm K-J. Leaking of fillers in dental composites. J Dent Res 1983;62(2):126-130. DOI: 10.1177/00220345830620020801.

26. Ayatollahi M, Yahya MY, et al. Effects of temperature change and beverage on mechanical and tribological properties of dental restorative composites. Mater Sci Eng C Mater Biol Appl 2015;54: 69-75. DOI: 10.1016/j.msec.2015.05.004.

27. Yesilyurt $\mathrm{C}$, Yoldas $\mathrm{O}$, et al. Effects of food-simulating liquids on the mechanical properties of a silorane-based dental composite. Dent Mater J 2009;28(3):362-367. DOI: 10.4012/dmj.28.362. 